\title{
METÁFORA Y METONIMIA EN LA CONSTRUCCIÓN DEL ESPACIO CONCEPTUAL Y LINGÜÍSTICO EN LA PRÁCTICA DE LA ATENCIÓN PLENA
}

METAPHOR AND METONYMY IN THE DEVELOPMENT OF THE CONCEPTUAL AND LINGUISTIC SPACE OF MINDFULNESS PRACTICES 
El estudio de la experiencia del ser y de la consciencia no es nada nuevo; los conceptos tratados en este artículo, tampoco. Su aportación más relevante pretende ser la propuesta de un modelo de representación de parte de esta experiencia (esto es, la percibida mediante la práctica de la atención plena) a través de parámetros básicos, establecidos y reconocidos dentro del paradigma cognitivo. Partiendo de la perspectiva de la lingüística cognitiva, se presenta lo que se denomina el 'Modelo Cognitivo Idealizado (MCI) de la contemplación', cuya estructura se describe con la ayuda de ejemplos extraídos de un corpus que compila la producción lingüística de instructores y principiantes en cursos de formación en atención plena. Concretamente, el artículo introduce primero el espacio que se crea en el practicante y que posibilita la percepción de los fenómenos a observar durante los periodos de atención consciente; tras ello propone y describe, a través del mencionado MCI, la integración de estructura preconceptual y conceptual que permite experimentar este 'escenario de observación' y captar los fenómenos que en él acontecen. El artículo concluye con una serie de consideraciones sobre los datos en él manejados, así como diversas líneas de investigación derivadas de la aquí presentada y sus aplicaciones en diferentes campos.

Palabras clave: atención plena, lingüística cognitiva, interacción lenguaconceptualización, Modelos Cognitivos Idealizados, reciclaje de estructuras

The study of consciousness and the 'experience of being' is not new, neither are the concepts addressed in this paper. One of its most relevant contributions is the introduction to a new model of representation of part of this experience (that is, the experience perceived by meditators during the practice of mindfulness) grounded on basic, well-established and acknowledged parameters within the cognitive paradigm. Departing from a cognitive linguistics perspective, the paper presents the 'Contemplation' Idealized Cognitive Model (ICM) and describes its structure with the help of a series of examples extracted from a corpus compiled out of the linguistic production of instructors and novices in mindfulness courses. More concretely, the paper firstly introduces the space that emerges in the meditator's consciousness, a space that enables the perception of the observed phenomena during 'mindful' periods. Then it describes how the mechanics of the aforementioned ICM paves the way for the integration of preconceptual and conceptual structure, and how this very integration allows experiencing the 'observer's scenario' and hence consciously apprehending the phenomena that occur therein. The paper concludes with a series of considerations concerning the data handled in it, different lines of research stemming from the one proposed in the study, and potential applications in different fields.

KEYwORDS: mindfulness, cognitive linguistics, language-conceptualization interaction, Idealized Cognitive Models, structure recycling

FECHA DE RECEPCIÓN: 15/11/2015

FECHA DE ACEPTACIÓN: 20/01/2016 


\section{METÁFORA Y METONIMIA EN LA CONSTRUCCIÓN DEL ESPACIO CONCEPTUAL Y LINGÜIISTICO EN LA PRÁCTICA DE LA ATENCIÓN PLENA}

\section{METAPHOR AND METONYMY IN THE DEVELOPMENT OF THE CONCEPTUAL AND LINGUISTIC SPACE OF MINDFULNESS PRACTICES}

Antonio-José Silvestre-López Universitat Jaume I

\section{Introducción}

La práctica de la atención plena implica atender conscientemente a todo lo que sucede en el momento presente, integrando y aceptando, sin juzgar, los fenómenos que ocurren tanto en el entorno como en nuestro interior. Kabat-Zinn (2003: 145) la define como "the awareness that emerges through paying attention on purpose, in the present moment, and nonjudgmentally to the unfolding of experience moment by moment". También se concibe como una habilidad inherente que puede ser desarrollada por cualquier persona a través de diferentes técnicas o prácticas meditativas (Soler et al., 2014: 1). ${ }^{1}$

\footnotetext{
${ }^{1}$ En el campo de la psicología, mindfulness se concibe como un rasgo disposicional o como un estado que todos podemos desarrollar y experimentar (Cebolla et al., 2014; García Campayo y Demarzo, 2015: 18). Sin embargo, debido a que la meditación es uno de los caminos más directos para desarrollar la atención ple-
} 
Originaria de prácticas budistas orientales, los beneficios físicos y mentales de la atención plena han propiciado su expansión en occidente en una creciente variedad de contextos, desde el desarrollo personal hasta el mundo de los negocios, el deporte, la educación y, sobre todo, la salud mental (Miró y Simón, 2012; Mañas et al., 2014). En este ámbito, la psiquiatría y la psicología clínica y experimental han demostrado científicamente los efectos positivos de esta práctica en el tratamiento de diferentes trastornos emocionales, de atención y ansiedad (cf. Cebolla et al., 2014); de hecho hoy en día la atención plena es parte integral de diversos tipos de terapia y programas de reducción de estrés (cf. Baer y Krietemeyer, 2006). Como consecuencia, el número de publicaciones científicas en estos campos ha aumentado exponencialmente en los últimos años, la mayoría de las cuales da cuenta de beneficios mensurables identificados en la muestra estudiada así como efectos positivos en contextos clínicos, sociales y del trabajo.

\subsection{Dimensión lingüistica de la atención plena}

Es posible encontrar estudios pertenecientes a distintas perspectivas que analizan el componente del lenguaje con objetivos concretos. Partiendo de perspectivas fenomenológicas, algunos de ellos enfocan su análisis en la descripción

\footnotetext{
na, es frecuente el uso de términos como 'meditación' o 'meditación con atención plena' para hacer referencia (metonímicamente) a la práctica de la atención plena en sí. En este artículo utilizaremos los términos 'meditación' y 'meditador' en sentido general, es decir, para hacer referencia tanto a la práctica como a los practicantes.
} 
verbal de las experiencias de grupos particulares de sujetos como medio para acceder a las características y naturaleza cualitativa de los fenómenos internos (Hulburt, 2011) o a las impresiones subjetivas de la experiencia de la atención plena (Francesconi, 2010). Dentro del campo de la psicología algunos estudios han abordado la conveniencia del uso del lenguaje en la práctica de la atención plena y suelen concebirlo como un obstáculo que hay que superar puesto que su uso implica la activación de asociaciones cognitivas, sesgos y filtros culturales (Hayes et al., 2001) que pueden dificultar la tarea de atender adecuadamente al momento presente (Hayes y Shenk, 2004: 251). Dentro del mismo campo, otros estudios han analizado el papel de los marcadores lingüísticos como un componente clave para medir el desarrollo de habilidades mindfulness (Collins et al., 2009). Los psicólogos han llegado a descomponer mindfulness en diversas facetas relacionadas con constructos mensurables cuantitativamente; en este sentido, estudios como Soler et al. (2014) han evaluado incluso la idoneidad de la faceta 'etiquetado verbal' en relación con variables de práctica de meditación. Finalmente, estudios destacables como Varra et al. (2009) y Eisendrath et al. (2011), enfatizan la importancia del uso del lenguaje figurado y metáforas creativas en el contexto clínico de la atención plena como recurso para lograr fines terapéuticos específicos dentro del marco de la Terapia de Aceptación y Compromiso y la Terapia Cognitiva Basada en Mindfulness

El componente lingüístico, así pues, ha recibido diversos grados de atención en relación con la práctica y estudio de la atención plena; atención escasa, sin embargo, en com- 
paración con el resto de estudios centrados en los beneficios sobre la salud. Por otro lado, la mayoría de estudios realizados hasta la fecha parten de áreas como la psicología o la fenomenología, y actualmente tampoco es posible encontrar estudios que analicen esta dimensión desde la perspectiva científica de la lingüística (Silvestre-López, 2016). El trabajo aquí presentado pretende abrir una trayectoria en este sentido, abordando el estudio del discurso de la atención plena desde la perspectiva de la lingüística cognitiva.

\subsection{Objetivos y fuentes de datos}

El objetivo de este artículo es realizar una aproximación a la experiencia de la atención plena principalmente a través del prisma de la lingüística cognitiva. Este propósito se concreta en dos partes diferenciadas. Por un lado, se proporciona una introducción al espacio que se experimenta al practicar la atención plena (el espacio de presencia en el momento presente del que hablan los meditadores), ${ }^{2}$ y se discute la propuesta de su concepción como un espacio no conceptual (Varela et al., 1991: 26) cuyas características pueden identificarse y ser modeladas desde la lingüística cognitiva. Por otro lado, este estudio integra este 'espacio no conceptual' como parte de un modelo primordial de representación de la experiencia, es decir, un MCI (Lakoff, 1987) que da pie a la elaboración de toda una serie de conceptualizaciones propias derivadas de la experiencia de la práctica de la

\footnotetext{
${ }^{2}$ Esto es, el espacio que se crea en el meditador y que posibilita la percepción de los fenómenos a observar, tanto físicos como mentales, durante los periodos de atención consciente.
} 
atención plena. En este contexto, y atendiendo al objetivo arriba descrito, metáfora y metonimia se erigen como dos pilares fundamentales en la construcción de dicho modelo y en la caracterización del espacio conceptual y lingüístico de la práctica de la atención plena.

La perspectiva cognitiva cuenta con herramientas potentes para la descripción de la experiencia de la meditación con atención plena, no únicamente en términos de representación mental y conceptualización de los fenómenos de observación, sino también a través del análisis de la producción lingüística de practicantes de atención plena como un punto de partida para identificar posibles patrones de representación mental y conceptualización de la experiencia (Chalmers, 1996: 217; Silvestre-López, en prensa).

Nuestro análisis se centra en la interacción oral de instructores y alumnos en contextos de formación en atención plena, concretamente en el discurso producido por los participantes de dos cursos de iniciación a la práctica de la atención plena organizados e impartidos por dos psicólogos cualificados en una universidad española. Los cursos se ofertaron a toda la comunidad universitaria (alumnos y personal de la universidad) y tuvieron una matrícula media de 20 participantes. Al tratarse de cursos de carácter introductorio, los 'meditadores noveles' tenían escasa o ninguna experiencia en meditación con atención plena. La duración total de cada curso fue de nueve horas estructuradas en seis sesiones semanales de hora y media de duración. La producción oral de los participantes en cada una de las sesiones se recopiló con la ayuda de una grabadora de audio que los instructores dejaron en el centro de la 
sala. Posteriormente, las grabaciones se transcribieron y se agruparon en un conjunto de documentos electrónicos que constituyen el corpus de datos lingüísticos utilizado en este estudio. Los contenidos del corpus se analizaron manualmente siguiendo diversos pasos. Primeramente, se revisó el corpus con el objeto de identificar 'tópicos' o temas recurrentes, es decir, áreas del corpus donde los interlocutores hablan de experiencias muy comunes y frecuentes en el contexto de la atención plena. Algunos de los más comunes de entre los identificados fueron, por ejemplo, 'espacio de presencia,' 'eventos físicos', 'percepciones', 'sensaciones', 'observador', 'idea del self', 'emoción' o 'pensamiento'. Una vez obtenido este mapa de temáticas recurrentes el siguiente paso fue identificar expresiones lingüísticas utilizadas por los interlocutores para tratar cada tema. De entre la variedad de expresiones lingüísticas se encuentran aquí expresiones metonímicas y metafóricas utilizadas frecuentemente por los hablantes para caracterizar su experiencia relativa a eventos internos como emociones y pensamientos de una forma más vívida y comprensible para sus interlocutores. Este artículo se basa en una pequeña parte de los resultados obtenidos en este análisis y presenta, principalmente a partir de la sección 4, una selección de algunos de los ejemplos más representativos derivados de las temáticas 'espacio de presencia', 'observador' y, sobre todo, 'pensamiento'. 


\subsection{Estructura}

Este artículo se estructura en cinco secciones principales. Tras una breve introducción, en la sección 1, a la relación entre la experiencia de la atención plena y el uso del lenguaje, la sección 2 presenta una visión particular de la metáfora asociada a su papel clave en la representación de fenómenos 'internos' como emociones y pensamientos. La sección 3 describe, desde una perspectiva genérica, lo que aquí se denomina el 'escenario de observación', para pasar a su integración, en la sección 4, dentro del 'MCI de la contemplación. Concretamente esta sección ofrece una descripción más pormenorizada del andamiaje de este escenario a través de parámetros como los esquemas de imagen y su interacción con otros elementos (metáforas, metonimias, guiones) que conforman lo que en el escenario acontece y que conjuntamente constituyen dicho MCI. Finalmente, la sección 5 presenta una serie de conclusiones e implicaciones para futuros estudios.

\section{Verbalización de experiencias vivenciales}

La experiencia de la meditación es inefable, porque es puramente vivencial. Paradójicamente, para describir la experiencia y transmitirla a los demás necesitamos el lenguaje. Por esta razón, tanto instructores como aprendices suelen realizar grandes esfuerzos para verbalizar su experiencia con el fin de transmitirla a los demás de una forma comprensible. Al plasmar esta experiencia lingüísticamente, nece- 
sariamente nos involucramos en un proceso en el que nos vemos forzados a 'reducir' la riqueza cualitativamente vivencial de una experiencia corporeizada a 'bloques conceptuales concretos' que transmitimos, con mayor o menor grado de fidelidad, a través de las posibilidades formales que permite nuestra lengua.

Precisamente por esto, al hablar de esta experiencia, los 'meditadores' suelen utilizar infinidad de ejemplos, recurren a comparaciones y analogías y utilizan una miríada de metáforas, por ejemplo, el espacio interno de observación y los pensamientos son frecuentemente (re)presentados como el cielo y las nubes, el mar en calma (baja frecuencia de pensamientos) en contraposición al mar embravecido (pensamientos asociados a las olas), o a través de la tranquilidad del agua de un lago truncada por las ondas generadas por pequeñas piedras (pensamientos) lanzadas en su interior, etc.

\section{La metáfora como recurso}

Este uso de la metáfora es frecuentemente consciente y/o deliberado (Steen, 2013) por parte de los 'narradores' de la experiencia meditativa, por ejemplo, a la hora de utilizar ejemplos para proporcionar una explicación más clarificadora y fiel a su propia percepción y experiencia de la meditación. Existen componentes de la metáfora, sin embargo, que suelen escaparse a la consciencia del narrador: proponemos que la metáfora está presente a un nivel mucho más profundo - independiente incluso del lenguaje - ya que se 
hace necesaria para aprehender muchos de los fenómenos 'internos' percibidos en la experiencia de la meditación; de este modo y en este nivel, la metáfora podría concebirse como un mecanismo ordinariamente inconsciente y no deliberado que facilita la percepción misma de los fenómenos internos. De este modo, por ejemplo, la percepción de un pensamiento (entidad no perceptible a través de los cinco sentidos físicos) y evaluación consciente de su naturaleza implica un proceso cognitivo asociado a una representación mental del objeto de percepción; la naturaleza de esta representación, como veremos, podría depender de los modelos cognitivos activados en este proceso, que a su vez pueden recuperar (por ejemplo, a modo de proyecciones entre dominios) parte de la estructura utilizada en el proceso de percepción de los fenómenos físicos.

\subsection{Delimitación de la concepción de la metáfora aquí planteada}

Aunque es posible encontrar algunas concepciones similares, se hace difícil encontrar correspondencias directas entre la visión de metáfora que aquí se describe y el resto de definiciones establecidas en este campo. Veamos algunos casos equiparables a grandes rasgos. Este tipo de metáfora podría relacionarse en primera instancia, dentro de la Teoría de la Metáfora Conceptual (TMC), con la concepción de metáfora primaria de Grady, ${ }^{3}$ en el sentido de que rescata la

\footnotetext{
${ }^{3}$ Grady sugiere: "Primary metaphors [...] are simple patterns [...] which map fundamental perceptual Concepts onto equally fundamental but not directly perceptual ones" (2007: 192).
} 
experiencia perceptual ${ }^{4}$ extraída de los 'sentidos físicos' para facilitar la percepción de fenómenos internos y mentales.

El campo de las metáforas de la percepción también ha sido estudiado en profundidad dentro de la TMC (cf. Ibarretxe-Antuñano, 2011, 2013a, 2013b para una aproximación detallada). Estas metáforas guardan una estrecha relación con la visión que aquí se propone. Derivadas de 'macrometáforas' como THINKING Is PERCEIVING (Lakoff y Johnson, 1999) o COGNITION IS PERCEPTION (Ibarretxe-Antuñano, 2013a), estas metáforas permiten estructurar dominios cognitivos relativamente abstractos a través de experiencias de percepción física derivadas de los cinco sentidos; por ejemplo, la famosa metáfora UNDERSTANDING/KNOWING Is SEING (Lakoff, 1996) estructura el dominio de la comprensión en términos del campo de la visión y puede generar expresiones como 'veo lo que quieres decir'. Mientras que la metáfora de la percepción (en su visión más esencial) ${ }^{5}$ toma como base el campo de la percepción física para estructurar otros dominios distintos a ella, la metáfora aquí descrita se concibe como un componente intrínseco asociado a la percepción misma, puesto que su presencia se hace necesaria para aprehender (percibir con la mente) los fenómenos internos (en otras palabras, actúa en la percepción consciente

\footnotetext{
${ }^{4}$ Aunque el DRAE no reconoce este vocablo, la mayoría de publicaciones académicas en el campo de la atención y percepción utilizan este término. Utilizamos aquí 'perceptual', en contraposición a 'sensorial', para dar cabida también a la aprehensión de fenómenos no captados directamente por los sentidos físicos (por ejemplo el pensamiento).

${ }^{5}$ Concebimos aquí las metáforas de la percepción (en su visión más 'pura’) como intrínsecamente asociadas a MCIs lingüístico-culturales, como el del 'observador' (cf. sección 4).
} 
de fenómenos 'no físicos'). Existe en ella de todos modos una proyección de estructura proveniente de dominios de percepción puramente física a dominios de percepción físico-mental; en este sentido podríamos hablar por tanto de una nueva categoría, una metáfora mental de la percepción. ${ }^{6}$

Dentro de una perspectiva más tradicional de la TMC, nuestra visión de la metáfora puede considerarse como perteneciente al orden de metáforas ontológicas descritas inicialmente por Lakoff y Johnson (1980), limitando su concepción en este caso a su carácter mental, es decir, al poder clarificador de estas metáforas en beneficio de la conceptualización de los fenómenos internos percibidos como son los pensamientos, independientemente de que incidentalmente llegue a reflejarse a través de realizaciones lingüísticas particulares.

La TMC ha sido en los últimos años sometida a revisión por diversos psicólogos y lingüistas (Gibbs, 2011; Evans, 2013; Steen, 2014) en la que se establece, en términos generales, una separación significativa entre metáfora a nivel conceptual y la metáfora a nivel lingüístico-discursivo. En este sentido, y dentro de una perspectiva psicológica, la metáfora aquí descrita podría equipararse a grandes rasgos a la noción de metáfora mental sugerida por Casasanto (2010, 2013). Casasanto (2010) distingue entre dos vertientes de la metáfora conceptual (según la TMC): la metáfora mental (que utilizamos para pensar) y la metáfora lingüística

\footnotetext{
${ }^{6}$ Dando un paso más allá, podríamos hablar incluso de una metáfora de percepción mental, dando a entender de este modo que la percepción mental podría considerarse (entroncando con la tradición budista) el 'sexto sentido', un sentido no físico a través del cual percibimos los estímulos 'de los objetos de la mente'.
} 
(que empleamos para hablar). La primera es independiente de la segunda y a través de ella establecemos relaciones entre diversos dominios, que pueden (o no) reflejarse eventualmente en el lenguaje. Casasanto defiende además que la formación de metáforas mentales viene determinada por diversos factores entre los que se encuentra la correlación experiencial, cultural y lingüística. En este sentido, las metáforas lingüísticas (aquellas reflejadas en el sistema de una lengua) son también un factor de influencia en el desarrollo de diversas proyecciones conceptuales a nivel mental puesto que la lengua es un factor experiencial más, otra clase de 'input', que tiene diversos efectos sobre nuestras representaciones mentales (cf. Thibodeau y Boroditsky, 2011, 2013; Steen et al., 2014). Casasanto (2013) hace una distinción más pormenorizada de las metáforas mentales dividiéndolas en correlacionales (experiencia directa con el mundo, de naturaleza inicialmente prelingüística) y analógicas (asociaciones lingüísticas). El tipo de metáfora mental del que hablamos es más similar al de la tipología correlacional, puesto que su desarrollo, según Casasanto, no depende inicialmente de la influencia lingüística, aunque no es menos cierto que el uso de un sistema lingüístico parece reforzar la activación de metáforas mentales particulares.

\subsection{Metáfora mental y aprehensión de los fenómenos internos}

La noción de metáfora aquí utilizada es la de una representación no lingüística que ayuda no sólo a conceptualizar, 
sino a percibir ${ }^{7}$ los fenómenos aquí descritos, sobre todo pensamientos y emociones. Esta metáfora es equiparable a la metáfora mental sugerida en Casasanto (2010, 2013), con el valor añadido de que ayuda a crear una representación mental del pensamiento, aunque no es una metáfora del pensamiento propiamente dicha; es decir, no es que pensemos (p. ej., en fenómenos abstractos) a través de estas metáforas o representaciones mentales, sino que estas representaciones mentales (a modo de simulación o imaginería mental; cf. Bergen, 2012) permiten la percepción del pensamiento (o pensamientos) en sí. Proponemos aquí, en definitiva, que el componente profundo de la metáfora del que hablábamos al inicio de esta sección está presente en la percepción mental de las emociones y la identificación de los pensamientos.

\subsection{El papel de la metáfora lingüistica}

La cuestión de si la existencia de metáforas lingüísticas constituye, en todos los casos, evidencia de la existencia de patrones metafóricos similares a nivel de pensamiento es todavía una cuestión de debate. Sin embargo, además de estudios de corte psicológico como Gibbs (2011) o Casasanto (2010, 2013), propuestas de corte lingüístico como Ruiz de Mendoza (2014) o Steen (2014) apuntan hacia la posibilidad de estudiar la metáfora lingüística o discursiva como una fuente de indicios de potenciales metáforas conceptuales. Del mismo modo, el análisis de la producción lingüística

\footnotetext{
${ }^{7}$ La noción de ception propuesta por Talmy (1996) adquiere aquí importancia. En este sentido, la metáfora podría considerarse como un catalizador de las 'cepciones' experimentadas por el individuo.
} 
de meditadores se puede concebir en este contexto como una vía para recabar evidencia lingüística de potenciales conceptualizaciones (en este caso, de base metafórica) de la experiencia cuya naturaleza - a pesar de ser subjetivamente aprehensibles a través de la experiencia directa 'en primera persona'- y existencia objetiva a nivel mental ha de ser corroborada mediante experimentos de orden psicológico o psicolingüístico.

\section{El escenario de la atención plena: una primera aproximación al modelo de 'percepción interior'}

Dentro del modelo de (per)cepción ${ }^{8}$ de los fenómenos internos es frecuente, por ejemplo, objetificar los pensamientos,

\footnotetext{
${ }^{8}$ A pesar de que la mayor parte de la información que procesamos proviene del sentido de la vista (Lakoff y Johnson, 1999), la aprehensión de los fenómenos (internos y externos) que ocurren en el momento presente prestando atención plena aglutina información recibida a través de todos los sentidos. A este nivel de experiencia, la información proveniente de los sentidos puede ser potencialmente reciclada para la conceptualización del pensamiento. Por este motivo, utilizamos 'percepción' en lugar de 'observación' para reforzar este componente holístico de la atención plena, pues el mero hecho de utilizar 'observación' impone una restricción de la experiencia. En un nivel más externo de experiencia, la primacía del sentido de la vista sobre el resto ha propiciado su explotación para la concepción del pensamiento en la mayoría de lenguas, a pesar de que, como apunta Ibarretxe-Antuñano (2013a, b), la asociación entre visión y cognición no es universal, sino relativa a modelos culturales y lingüísticos. El modelo que hemos heredado lingüística y culturalmente explota precisamente la metáfora del observador, una metáfora emparentada directamente con las 'metáforas de la percepción', para hacer referencia a la experiencia de la atención a los fenómenos del momento presente, de modo que es común referirnos a esta práctica como prácticas 'contemplativas'. La redacción de este artículo requiere el uso del lenguaje y por tanto en algunos momentos utilizaremos léxico de la percepción visual para referirnos a la 'contemplación' de los fenómenos percibidos. Es ne-
} 
es decir, 'convertirlos', mediante metáforas ontológicas tan convencionales como LOS PENSAMIENTOS SON OBJETOS, en entidades definidas u objetos con cualidades típicamente físicas. Esto nos permite conceptualizar los pensamientos como entes que surgen, vienen y van, aparecen y desaparecen, que captan nuestra atención de diversas formas y nos producen sensaciones, positivas y negativas. Las emociones pueden conceptualizarse también como entidades ajenas al experimentador, muchas veces con voluntad propia, que ejercen una fuerza sobre aquél y lo incitan a ciertos comportamientos, por ejemplo, llevándolo a hacer o decir cosas que de otro modo no habría hecho o dicho (Kövecses, 1990, 2000).

Ciertamente, la objetificación ayuda a aprehender más firmemente fenómenos tan 'escurridizos' como el pensamiento o las emociones y las sensaciones que de ellos se derivan; pero además, la objetificación de estos fenómenos requiere necesariamente la activación de un escenario previo, un espacio primordial donde estos fenómenos acontecen. Este escenario particular integra una serie de parámetros (principalmente de carácter gestáltico) que proporcionan la estructura preconceptual necesaria para la aprehensión conceptual de fenómenos 'internos' como pensamientos o emociones, entre otros. Entre dichos parámetros se en-

\footnotetext{
cesario hacer notar, sin embargo, que el uso de este vocabulario obedece a un modelo lingüístico-cultural preestablecido, que el autor de este artículo explota, en momentos clave de su discurso, para agilizar la comprensión del lector (al acercar el modelo popular y compartido al campo de la experiencia, más amplia, vivida directamente).
} 
cuentra una serie de patrones de posicionamiento e interacción que introducimos a grandes rasgos a continuación.

Una de las consecuencias de la existencia de estos parámetros es la distinción consciente entre el observador y lo observado, es decir, la separación pensamiento-pensador asociada dentro de las terapias cognitivo-conductuales al constructo de defusión cognitiva. ${ }^{9}$ Esta separación implica necesariamente la activación de un punto de vista ventajoso y una perspectiva de observación ${ }^{10}$ ligada a una distancia mínima que posibilita la identificación del fenómeno observado como algo distinto del observador (Silvestre-López, 2016).

El observador, como 'posibilitador' de la experiencia, suele posicionarse en el centro de este escenario, ${ }^{11}$ desde donde disfruta de una perspectiva ventajosa para captar los

\footnotetext{
${ }^{9}$ La defusión cognitiva se ha definido como la habilidad para observar los propios pensamientos y sentimientos como eventos mentales pasajeros, en lugar de percibirlos como realidades o verdades acerca de uno mismo (Safran y Segal, 1990; Kerr y Littenberg, 2011). Este constructo empieza ya a desarrollarse en las primeras etapas del aprendizaje de la atención plena (Hölzel et al., 2011), se ha asociado con una menor reactividad emocional a los eventos externos o internos (Shapiro et al., 2006) y con una mejor condición de salud mental (Soler et al., 2014). Se trata pues de un constructo central asociado a la práctica de la atención plena cuya propia definición se explicita a través de procesos de enmarcamiento metafórico (percibir pensamientos como eventos mentales / realidades) y metáforas básicas como la del observador, de la que hablaremos más adelante.

${ }^{10}$ El lector con conocimientos en lingüística cognitiva posiblemente ya habrá establecido una relación entre estos parámetros y algunas dimensiones de estructuración conceptual (dimensions of construal) descritas por Langacker (cf. p. ej., 2008: 55-85). Traducción de 'construal': Ibarretxe-Antuñano y Valenzuela (2012).

${ }^{11}$ Aunque es posible adoptar perspectivas alocéntricas mediante visualizaciones o disociaciones (cf. Kross y Ayduk, 2011) la egocéntrica es la representación canónica del individuo en el espacio (Evans, 2010).
} 
fenómenos que acontecen en una relativa periferia (dependiendo de la distancia) con respecto a su posición. Además de la distancia observador-objeto observado, la relación centro-periferia también es importante por tanto en este escenario, siendo el centro además concebido como un eje vertical (identificado con el propio observador) derivado de la perspectiva adoptada ordinariamente en la percepción y observación de los fenómenos 'externos', es decir, de nuestro entorno físico (posición canónica con el tronco erecto y la cabeza erguida, de pie, andando o sentados).

El escenario se representa como una 'realidad presencial', como un espacio de presencia donde acontecen todos los fenómenos, un sutil contenedor que, abarcando toda la realidad experimentada en el momento presente, permite la formación y la existencia de los fenómenos aprehendidos por la consciencia durante el proceso de observación.

Como veremos en la sección 4, en este espacio, por ejemplo, nos pueden 'invadir' pensamientos negativos inesperados que 'surgen' por cuenta propia, sin haber sido recordados o 'traídos' voluntariamente al aquí y al ahora, y que 'entran sin permiso' en nuestro espacio de percepción abriéndose camino desde la periferia hacia nuestro centro, con un poder de influencia equivalente a su distancia con este último. Por otro lado, también podemos encontrarnos con que los pensamientos 'nos pueden llamar la atención' de diversos modos e incluso con que - tras haber discurrido bastante tiempo y sin habernos dado cuenta- nosotros mismos 'nos hemos ido' tras un pensamiento que tiene 'un gran poder de atracción' sobre nosotros; en ese momento, al darnos cuenta de la situación, podemos seguir 'inmer- 
sos' en ese pensamiento o bien tomar la decisión consciente de 'dejarlo ahí, donde está, y observarlo desde la distancia. La atención plena nos permite observar incluso comportamientos del pensamiento: podrá permanecer un tiempo -móvil o estático - ante nosotros, desvanecerse, acercarse, alejarse, atraernos, ejercer una influencia (efectos) positiva o negativa en nuestro estado actual, incitar algún tipo de reacción, etc.

Es por tanto en este espacio donde acontecen las conceptualizaciones (representaciones mentales) de la experiencia. El escenario en sí permite la existencia de éstas, de metáforas y representaciones particulares de fenómenos más o menos abstractos: el escenario proporciona las condiciones, el andamiaje para la construcción de todo este modelo de percepción y 'observación'. Es, por decirlo de algún modo, la conditio sine qua non para la existencia de estas percepciones, representaciones y conceptualizaciones.

\section{1. ¿Es este espacio un espacio mental?}

Se podría argumentar que este espacio es un 'espacio mental' en tanto que - tal y como hemos heredado a través de nuestro modelo cultural- en él aprehendemos los 'contenidos de la mente. Varela et al. (1991: 26) hacen referencia al espacio que se experimenta a través de la meditación en términos de "espaciosidad de la mente":

Meditators also report experiencing space and spaciousness of mind. A traditional metaphor for this experience is that mind is the sky (a nonconceptual background) in which different mental contents, 
like clouds, arise and subside. Experience of panoramic awareness and of space are natural outgrowths of mindfulness/awareness meditation.

Parte del modelo aquí propuesto hace referencia al espacio que se percibe en la práctica de la meditación (un espacio mental, de presencia, o 'del ser') desde la perspectiva de la lingüística cognitiva y propone que este "nonconceptual background" está formado ${ }^{12}$ precisamente por las gestalts preconceptuales mencionadas anteriormente. Éstas, formadas a través de nuestra experiencia diaria ordinaria de 'atención hacia el exterior', se reciclan para formar el andamiaje previo a la construcción del contenido conceptual que surge al prestar atención 'hacia nuestro interior'.

El espacio al que hacemos referencia no se restringe únicamente a la percepción de 'fenómenos mentales', sino que es más inclusivo en tanto que abarca cualquier fenómeno del entorno, de nuestro cuerpo físico, de nuestra mente. La concepción de este espacio como 'mental' adquiere así un sentido holístico en consonancia con la concepción de 'mente extendida', sugerida ya en el famoso artículo de Clark y Chalmers (1998). En ella, lejos de quedar relegada al órgano físico que la hace posible, el cerebro, los límites de la mente abarcan también el cuerpo y el entorno. El espacio 'mental' del que hablamos, por tanto, incluye todos los fenómenos del aquí y el ahora integrados en nuestra experiencia corporeizada.

${ }^{12}$ Entre otros parámetros, cf. sección 4. 


\section{2. ¿Un espacio de espacios? Integración de los fenómenos internos y externos}

La neuropsicología establece diversas distinciones del espacio personal entre las que destacan el espacio extrapersonal (fuera del alcance del brazo), peripersonal (al alcance del brazo) y personal (ocupado por el cuerpo) (Berntson y Cacioppo, 2009). La distinción de espacios propuesta en las siguientes líneas coincide con la anterior y aglutina un componente experiencial adicional: un espacio interconectado en el que es posible percibir el pensamiento y las emociones como componentes integrados con el resto de fenómenos. Así, la concepción del espacio más amplio abarca los límites de la percepción sensorial del observador (incluyendo la auditiva y la visual). El siguiente espacio más 'próximo' coincide con el espacio que envuelve inmediatamente al observador y que concuerda, en términos generales, con la noción de distancia personal descrita en la proxémica de Hall (1966). Es un espacio en el que, aun no coincidiendo con el cuerpo físico del observador, éste puede notar los efectos (p. ej., sentirse invadido, incómodo, reconfortado) de la presencia de otros elementos - no únicamente personas- con los que, debido a esta proximidad, puede interactuar. En otro nivel, el espacio que limita el cuerpo físico del observador se funde con el espacio inmediatamente interior, donde se experimentan las sensaciones y también los efectos físicos de las emociones (Kövecses, 2000). En este espacio, además, a un nivel más profundo, se abre la posibilidad de percibir las emociones a otros niveles (psicológico, mental), así como los pensamientos. La 'contemplación' 
de los fenómenos del momento presente abarca potencialmente (dependiendo de la apertura del foco o campo de atención) todas las dimensiones arriba mencionadas simultáneamente, de modo que todos los espacios se funden en uno, el 'espacio de percepción con atención plena', donde acontecen todos los fenómenos de la percepción, físicos o no. En definitiva, se trata de un espacio de presencia, de permanencia en el momento presente, en el que se unifica la experiencia de percepción externa e interna, sensorial, emocional y mental.

La integración de espacios 'externos e internos' es de hecho una de las claves de la atención plena, y como tal, una característica común del discurso de sus instructores (Silvestre-López, 2016), sobre todo en meditaciones guiadas de atención al momento presente. El siguiente fragmento, perteneciente a la producción lingüística de un instructor de atención plena, ejemplifica cómo elementos del espacio físico y, en este caso, pensamientos, se integran discursivamente en la misma experiencia:

(1) Cuando nuestro cuerpo se relaja, nuestra fisionomía, nuestra musculatura, se crea un espacio de tolerancia, de contemplación, en el que todo lo que sucede se contempla y tiene derecho a existir; en el que no hace falta cambiar nada, sólo contemplar esa interacción constante con el medio que te rodea; esa interacción con tus pensamientos. Igual que escuchas un sonido, que escuchas una voz, que ves una imagen, contemplas también un pensamiento. 


\section{El escenario del observador como MCI: aproximación desde la perspectiva cognitiva}

Hasta este punto nos hemos centrado en la descripción del 'escenario de la atención plena' de un modo general. El objeto de esta sección es estructurar esta descripción a través de parámetros propios de la lingüística cognitiva. Proponemos que el espacio en el que la consciencia advierte los fenómenos de la percepción y los efectos y consecuencias derivadas de esta interacción pueden concebirse como integrantes del 'modelo de observación'. Nos referimos a un modelo experiencial, un MCI que permite experimentar los fenómenos de la percepción 'interna' y que da acceso a conceptualizaciones particulares de esta experiencia.

En consonancia con las propuestas de Santiago et al. (2011) sobre el espacio mental de trabajo, ${ }^{13}$ sugerimos que estructuras gestálticas como los esquemas de imagen son la piedra angular sobre la que se construye, en este caso, el espacio de observación; de hecho éste puede describirse a través de una serie identificable de los mismos, incluyendo entre ellos elementos de dinámica de fuerzas (Johnson, 1987; Talmy, 2000). Dando un paso más, este estudio sugiere que estos esquemas de imagen emergen naturalmente gracias

\footnotetext{
${ }^{13}$ Santiago et al. proponen una visión de la memoria de trabajo basada en un 'mental workspace' estructurado con marcos de referencia similares a los utilizados en nuestra experiencia de percepción ordinaria y donde —en virtud de los requisitos de la conceptualización o la tarea a realizar en cada momento- es posible recuperar estructuras adicionales como por ejemplo esquemas de imagen. Es en este espacio, asimismo, donde acontecen contenidos concretos y se activan los modelos de representación del pensamiento abstracto necesarios para llevar a cabo la tarea requerida.
} 
a su interacción con otros tipos de estructura conceptual, tanto de corte estático como dinámico (esto es, elementos que conforman marcos y guiones y proyecciones metonímicas y metafóricas), que actuando conjuntamente se convierten en los catalizadores de la experiencia del espacio de contemplación. Éste es pues un sistema de elementos integrados en una simbiosis total y activa, conformando el MCI de la experiencia de la contemplación. El estudio de este MCI a través de datos derivados de la producción lingüística de meditadores nos permite obtener más detalles (de forma indirecta, en tanto que hablamos de producción lingüística) acerca de la existencia y naturaleza de este espacio previo, el espacio al que se accede a través de la experiencia directa y que suele experimentarse practicando la atención consciente.

\subsection{Reciclaje de estructuras antiguas}

El modelo de representación que proponemos tiene unas bases experienciales asentadas en gestalts desarrolladas a lo largo de nuestra experiencia con el mundo físico. Siguiendo las propuestas de Casasanto sobre el principio de exaptación, ${ }^{14}$ nuestra propuesta parte de la reutilización de estas estructuras preconceptuales (concretamente, esquemas de imagen derivados de y utilizados en nuestra

\footnotetext{
${ }^{14}$ Partiendo de una perspectiva evolucionista, Casasanto (2010: 455) utiliza la noción de exaptación (la idea de que a lo largo de su evolución los organismos reciclan estructuras viejas para cubrir necesidades nuevas) para sugerir que la mente también reutiliza estructuras anteriores para usos nuevos. La reutilización que proponemos sigue los mismos principios, que por otra parte no son nuevos para la ciencia cognitiva.
} 
experiencia externa primordialmente) en la percepción y aprehensión de otros fenómenos más sutiles como los pensamientos y las emociones, es decir, para 'observar el mundo interior.' La metáfora del observador (junto con el resto), de hecho, viene propiciada por la 'imposición' de patrones de percepción exterior (los que ordinariamente estamos 'más acostumbrados' a utilizar, puesto que ayudan a nuestra supervivencia inmediata en el entorno) hacia la percepción del interior.

Utilizando términos de Casasanto, nuestra propuesta estriba en que realmente reciclamos los mismos recursos que utilizamos para percibir ordinariamente los fenómenos físicos de nuestro entorno y desenvolvernos en él. Sin embargo, al atender al interior no podemos percibir físicamente fenómenos como los pensamientos. Es en este punto donde interviene, de forma natural, la metáfora. Dicho de otro modo, metáforas 'objetificadoras' como las arriba mencionadas ${ }^{15}$ se activan efectivamente para facilitar la reutilización de estos recursos (por ejemplo, simular la percepción de objetos en el espacio físico) en la percepción de los fenómenos internos.

\subsection{El MCI de la contemplación de los fenómenos internos:} introducción e interacción de sus componentes básicos

\footnotetext{
Al menos cuatro parámetros básicos actúan al unísono en cuatro niveles distintos para configurar lo que experiencial-

${ }^{15}$ Nos referimos a las metáforas con función objetificadora como por ejemplo LOS PENSAMIENTOS SON OBJETOS, descritas en la sección 3, que se desarrollarán con más detalle en los siguientes párrafos.
} 
mente se puede denominar 'el MCI de la contemplación/observación. En este apartado los presentamos por separado para una comprensión más clara.

\subsubsection{Metonimia primordial de la fragmentación del individuo}

Generalmente vivimos identificados con nuestros pensamientos y, al no ser conscientes de ellos, éstos pueden tomar poder sobre nosotros y guiar nuestra acción cotidiana. Una de las primeras tareas de los instructores de atención plena es precisamente ayudar a los principiantes a 'darse cuenta' de sus emociones y pensamientos, y sobre todo a aprender a desidentificarse de ellos. Este es el comienzo de la 'libertad' del meditador, puesto que tomar conciencia del constante flujo de pensamientos es justamente el primer paso para erradicar su potente influencia sobre nosotros. La desidentificación del individuo con el pensamiento ( $\mathrm{y}$, por ende, la defusión cognitiva) es pues un requisito para la percepción del pensamiento en sí.

Esta desidentificación puede concebirse como un efecto metonímico en el que, partiendo de la estructura del esquema de imagen parte-todo, un todo inicialmente fusionado se fragmenta y se convierte en un todo fragmentado. ${ }^{16} \mathrm{El}$ todo fusionado se corresponde con la identificación total del individuo con 'sus' pensamientos (identificación que impide

\footnotetext{
${ }^{16}$ En términos metonímicos (Peña y Ruiz de Mendoza, 2009), el todo fusionado se correspondería con el dominio matriz, y el todo fragmentado mostraría el dominio matriz con una serie de subdominios (fragmentos) identificables y a disposición de proyecciones metonímicas adicionales que enfaticen su relevancia sobre el resto de la estructura que configura el dominio matriz.
} 
obtener la perspectiva necesaria para crear una distancia y desidentificarse). ${ }^{17}$ La fragmentación de esta unión inicial (es decir, el efecto metonímico a través del que se focalizan partes identificables de lo que inicialmente era un todo irreducible) hace posible este distanciamiento en tanto que permite al observador focalizar la atención en un pensamiento e identificarlo como algo distinto al observador que lo experimenta.

Se pueden distinguir distintas fases de fragmentación que se corresponden con el 'grado de consciencia' que adquiere el meditador a través de la práctica asidua. Comentaremos dos de ellas a modo de ejemplo. ${ }^{18}$ En la primera fase el todo fusionado se comienza a fragmentar. En ella el individuo comienza a darse cuenta de que, siendo él un todo, es posible comenzar a identificar los fragmentos que

\footnotetext{
${ }^{17}$ Esta identificación suele conceptualizarse en una posición o ubicación espacial en la que pensador y pensamiento coinciden totalmente (no hay distinción consciente), o bien de un modo en el que el pensador está involucrado (rodeado, dentro) en un pensamiento, de un modo similar al que sucede con los estados, y esta situación le impide 'ver' el pensamiento.

${ }^{18}$ Fases más avanzadas (cuya descripción cae fuera del objeto de este trabajo) se dirigen hacia una concepción totalitaria y unificadora de la existencia. De este modo, el todo fragmentado aquí descrito, una vez aprehendido por la consciencia y observado correctamente -en términos de la visión clara o entendimiento correcto de la realidad del que hablan las corrientes budistas (cf. Mañas et al., 2014) - comienza a integrarse en un proceso de unificación todavía mayor. Un estado de consciencia más desarrollado va acompañado de una comprensión más profunda de la existencia del observador en relación con un todo que, paradójicamente, da lugar a una consciencia no diferenciada de todas las cosas (aproximada a la concepción de no-dualidad) en la que la distinción observador-observado se desvanece. Las paradojas surgen en este punto porque en él comienzan a desafiarse los modelos cognitivos a través de los que filtramos ordinariamente nuestra experiencia de la realidad. La metonimia primordial, por tanto, cierra en última instancia un ciclo en el que no las partes, sino el todo, aparece como foco claro de consciencia.
} 
lo componen. En otras palabras, el individuo (dominio matriz) se desidentifica del pensamiento (subdominio). A pesar de esta desidentificación, el observador puede percibir el pensamiento como una parte tan intrínseca y cercana al yotodo que la influencia sobre él es todavía muy importante. Aunque no hay ninguna metonimia lingüística involucrada, (2) ilustra una estructuración conceptual aproximada derivada de esta metonimia mental:

(2) Vivo con el sentido de quién soy dependiendo de lo que me digan mis pensamientos.

En una segunda fase, gracias a la práctica de la meditación con atención plena, el dominio de la percepción se ha expandido, ${ }^{19}$ de modo que el individuo comienza a verse a sí mismo como una conciencia integrada en algo mayor que le sobrepasa. En otras palabras, el individuo ahora se identifica con una de las múltiples partes (subdominios) que pueden llegar a componer un todo mayor (dominio matriz) y comienza a percibir los pensamientos, al igual que el resto de los fenómenos de la percepción (tanto emociones como fenómenos físicos) no como partes propias, sino como integrantes de ese todo que le rodea. ${ }^{20} \mathrm{El}$ grado de distanciamiento entre observador y objeto observado (independien-

\footnotetext{
${ }^{19}$ La distancia entre observador y fenómenos observados se ha incrementado, favoreciendo así una perspectiva más amplia para percibir elementos anteriormente irreconocibles. En este estadio es posible incluso reconocer el ego como algo distinto a la consciencia observadora (Brown et al., 2008), de modo que ahora es incluso posible observar patrones egoicos de reacción y conducta, anteriormente imposibles de percibir.

${ }^{20}$ Esto no impide que la consciencia observadora se perciba en el centro, ya
} 
temente de su naturaleza) es por tanto mayor. La mayoría de ejemplos propuestos en este artículo ilustran la estructuración conceptual que subyace a esta fase. El siguiente ejemplo puede ayudar a comprender la estructuración conceptual de la que hablamos:

(3) Sabes que eso [evento posterior] va a pasar después. Ahora vas al baño, estás centrado en esa experiencia en concreto. Eso es expandir la atención, no volcarla hacia el futuro, sino a lo que en ese momento estás experimentando; entonces se va abriendo también un espacio en el cual, como estás atento a lo que estás experimentando en ese instante, lo que está sucediendo es que al mismo tiempo tú mismo te ves a ti experimentando y por eso empiezas a conocerte mejor, y a conocer cómo te vinculas con las cosas de la realidad, y luego pues, surgen otras experiencias más intensas, depende del nivel.

Autores como Lakoff asignan un valor metafórico a un fenómeno similar al que aquí consideramos metonímico (concretamente al de la primera fase). A través de la metáfora del scattered self, Lakoff (1996: 12) lleva a cabo la separación del selfy partes que lo conforman para dar cuenta de la existencia de expresiones lingüísticas como 'pull yourself together'. La metonimia aquí descrita trasciende el carácter lingüístico, y proponemos que, en la línea de las metáforas mentales sugeridas por Casasanto (2010), podría considerarse una metonimia mental cuyo efecto, sugerimos, es

que este punto de vista refleja los patrones básicos de percepción en el mundo exterior. 
precisamente el que permite que surja una consciencia observadora, una entidad perceptora capaz de distinguir conscientemente y con mayor nitidez tanto el acto de percibir como las entidades percibidas.

Como tal, esta metonimia es realmente el 'demiurgo' del MCI de la observación, es la fuerza impulsora que propicia la desidentificación primordial que a su vez desencadena otra serie de efectos, como por ejemplo el de la perspectiva o la distancia entre perceptor y percepto. Estos efectos, a nivel preconceptual, coinciden con los esquemas de imagen mencionados anteriormente ( $\mathrm{y}$ en la sección que sigue), activados y reciclados automáticamente para poder procesar esta 'nueva realidad'; los efectos a nivel conceptual dan lugar a diferentes estructuraciones conceptuales de la experiencia.

A pesar de su carácter mental, sin embargo, la presencia de esta metonimia se expresa lingüisticamente de diversos modos. De hecho el análisis de la metonimia en la producción lingüística del informante proporciona información sobre estructuraciones conceptuales particulares ${ }^{21}$ de la experiencia que podrían llegar a asociarse a un mayor o menor grado de desidentificación (en una situación determinada)

\footnotetext{
${ }^{21}$ Peña y Ruiz de Mendoza (2009) defienden el papel de la metonimia como catalizador de operaciones a nivel preconceptual, y Bierwiaczonek (2012: 258261) describe diversos procesos metonímicos a nivel de percepción, abogando incluso por la 'metonimia perceptual' como la forma más básica de metonimia. De un modo similar, concebimos aquí la metonimia como un proceso que subyace a estrategias de estructuración conceptual relacionadas con la percepción (principios gestálticos), como por ejemplo la distinción entre figura y fondo como parte(s) de un todo (Langacker, 2008). En relación con estos parámetros, el entrenamiento en atención plena desarrolla nuestra habilidad para proporcionar el estatus de figura a elementos que ordinariamente aparecen como fondo o incluso la habilidad para proporcionar estatus de figura al fondo en su conjunto.
} 
e incluso al grado de consciencia observadora desarrollado en función de esta desidentificación. ${ }^{22}$ Estos usos entroncan directamente con el desarrollo de las habilidades de la atención plena y la perspectiva "descentralizada" que sugieren Collins et al. (2009: 743):

... the language individuals use to describe their experience of mindfulness may also serve as a behavioral indicator of the development of mindfulness. In fact, the ability to describe observed phenomena by applying words comprises one component of mindfulness as it is currently defined (Baer, Smith, Hopkins, Krietemeyer, \& Toney, 2006). This ability may also be indicative of a "de-centered" or "metacognitive" perspective, which has been proposed to be an important mechanism by which mindfulness affects outcomes (Teasdale et al., 2002).

En este sentido, por ejemplo, el grado con el que el individuo, a lo largo de su discurso, se identifica (a través de estructuraciones conceptuales plasmadas lingüísticamente) con su mente o con su atención en lugar de con la consciencia que experimenta la existencia misma de la mente o de la atención es uno de los casos más recurrentes.

\footnotetext{
${ }^{22}$ En este sentido la evidencia lingüística proporciona datos cualitativos (tipología de elaboraciones lingüísticas utilizadas a lo largo del discurso de un iniciado, como parte de un corpus de datos compilado a lo largo del tiempo, mostrando su progresión) y cuantitativos (frecuencia de cada elaboración lingüística en dicho corpus) sobre dichas estructuraciones conceptuales. Son necesarios, sin embargo, experimentos de corte psicológico para comprobar si la asociación entre estructuración conceptual y grado de desidentificación es relevante y, en su caso, el grado de desidentificación derivado.
} 
(4) Pues a mí me cuesta, cuando me quiero dar cuenta estoy en 200.000 sitios. Intento volver otra vez pero en 30 segundos, creo que voy subiendo, me voy otra vez. O sea, me paso todo el rato luchando y de vez en cuando me doy cuenta de que no estoy aquí, porque el problema es que ni siquiera me doy cuenta de que me he ido...

(5) ... cuando se me despista la mente y se me va para un pensamiento intento volver a centrarme cómo entra la respiración, y cómo sale. Que viene otro pensamiento, pues lo mismo...

(4) y (5) pertenecen al discurso de dos principiantes dentro del curso de meditación. La presencia de la metonimia OBSERVADOR POR ATENCIÓN ${ }^{23}$ vehiculada en las expresiones en cursiva de (4) revela una estructuración conceptual en la que la consciencia observadora aparece fusionada con su parte mental y se identifica (metonímicamente) con la atención. Esta metonimia, sin embargo, no aparece en las expresiones de (5), cuya estructuración conceptual subyacente podría ser indicativa de un mayor grado de consciencia en tanto que el observador 'se da cuenta' de que es una parte (su atención, su mente), ${ }^{24}$ y no la totalidad de su ser consciente, la que 'se va tras el pensamiento'.

\footnotetext{
${ }^{23}$ Las metonimias Meta-en-Fuente denotan vaguedad conceptual por naturaleza en tanto que se parte del dominio matriz y no se perfila explícitamente el subdominio (meta) al que se hace referencia (Peña y Ruiz de Mendoza, 2009).

${ }^{24}$ En el sentido más purista, podría argumentarse que el uso de 'mente' en este contexto sintáctico es metonímico (no entraremos en posibles interpretaciones metafóricas). Ésta podría considerarse una metonimia del tipo PARTE-POR-PARTE (MENTE POR ATENCión) o incluso PARTE-POR-TOdo (Fuente-en-Meta), en cuyo caso la propia realización lingüística enfatiza y proporciona directamente el subdominio perfilado, que da cuenta por sí mismo de la distinción conceptual observador-atención que nos ocupa.
} 


\subsubsection{Esquemas de imagen}

El conjunto de esquemas de imagen que componen el andamiaje del 'espacio de presencia' es complejo. Silvestre-López (en preparación) clasifica y analiza con detalle la interacción de algunos de los más relevantes entre los que se encuentran CONTENCIÓN, CENTRO-PERIFERIA, CAMINO (RECORRIDO), PROXIMIDAD (DISTANCIA), VERTICALIDAD, HORIZONTALIDAD, CONEXIÓN, EQUILIBRIO, etc. En esta sección describimos sucintamente la presencia de algunos de ellos a través de un breve comentario sobre varios fragmentos de la producción lingüística de dos instructores en atención plena.

(6) [...] simplemente, igual que respiras, que entra y sale aire en tu cuerpo, permites que entren y salgan pensamientos.

(7) Si surgen pensamientos, daos cuenta de cuándo esos pensamientos os han impedido atender a la actividad [lavar los platos], y volved otra vez a la realidad, al presente. Cada vez que hagamos esto, estamos avanzando, tomamos conciencia de cómo el pensamiento nos ha invadido, nos ha absorbido y volvemos otra vez a lo que estamos haciendo. De ese modo aprendemos a elegir, a elegir estar en el presente.

La existencia del espacio de presencia se revela a través de innumerables sutilezas analizables en todos los ejemplos presentados en este artículo. Nos centraremos simplemente en algunas de las más obvias. La estructuración conceptual del espacio de observación en términos del esquema de imagen de CONTENCIón (incluyendo la lógica que lo constituye) 
se percibe en (6) a través de los pensamientos que 'entran y salen'. Asimismo, el mero uso de 'invadir' en (7) requiere necesariamente la activación previa de este espacio-contendor donde 'irrumpen' los pensamientos, además de una configuración específica de dinámica de fuerzas que justifica la conceptualización de pensamientos no deseados como entes 'intrusivos. ${ }^{25}$ En (7), además, se da una progresión, a modo de guion, en la que el pensamiento se aproxima, entra e invade el espacio, captura 'nuestra' atención (nos absorbe) y al tomar conciencia de ello automáticamente nos 'defusionamos' del pensamiento, retomamos la perspectiva necesaria para 'volver' al espacio asociado al momento presente.

La noción de movimiento, y por lo tanto la de CAMINo, junto con una perspectiva asociada a la concepción de un CENTRO-PERIFERIA como componentes del espacio de observación, es patente en los ejemplos anteriores, y se hace incluso más explícita en los siguientes a través de realizaciones como 'vienen y van' en (8), donde el pensamiento se aproxima, desde un punto inicial — probablemente externo al espacio más próximo al observador- hacia su ubicación particular, esto es, el centro de la escena.

(8) Si ves que a tu mente no le apetece contar, pues no cuentes. Si ves que vienen pensamientos y van, pues déjalos que vayan y vengan.

(9) Sí, normalmente cuando tú te estás cepillando los dientes y respirando y ves que los pensamientos están pasando, el hecho mis-

${ }^{25}$ De hecho algunas técnicas y terapias cognitivo-conductuales denominan a este tipo de pensamientos pensamientos intrusos (Barraca, 2011). 
mo de que tú te des cuenta de que están pasando, y te sitúes y veas eso como algo que pasa y lo dejas pasar, no te quedas con ningún pensamiento. Si te quedas enganchada a algún pensamiento, vuelve otra vez.

(10) ¿Crees en el pensamiento: tengo miedo? Si tú te identificas con ese pensamiento, vives asustado. Por lo tanto, acepta esa sensación, ese miedo, acepta cómo se convierte en un pensamiento, obsérvalo y desidentifícate de él. Eso no eres tú, en realidad [...]. Observa ese miedo, pero sepárate de él, tú no eres eso, no te identifiques a ti mismo como ese miedo que dices que eres.

La importancia de nociones como perspectiva y distancia (esquema de imagen DISTANCIA o PROXIMIDAD) se hace patente tanto en (7) como en (9), donde además el instructor verbaliza la percepción de perspectiva: 'te sitúes $y$ veas eso como algo que pasa'. Crear distancia (separando lo que inicialmente está fusionado en un mismo 'centro') es de hecho una estrategia básica para disminuir la influencia de 'entidades' que nos afectan negativamente, tanto física como mentalmente. Esta noción se perfila lingüísticamente de nuevo en la última oración del ejemplo (10). Nuestra experiencia corporeizada nos ayuda a generar asociaciones básicas entre nociones (o dominios) distintos (por ejemplo, tiempo y espacio, afecto y calor) dando lugar a metáforas correlacionales (Casasanto, 2013). De este modo, a través de nuestra experiencia cotidiana hemos ido generando una correlación funcional entre distancia e influencia que, proponemos, ha dado lugar a la metáfora correlacional INFLUENCIA ES DISTANCIA. Es esta metáfora la que se explota 
en ejemplos como (10), y la que nos permite tanto conceptualizar como abordar discursivamente la influencia entre dos entidades (no necesariamente físicas) en términos de proximidad o lejanía (a mayor proximidad, mayor influencia y viceversa).

La combinación CENTRO-PERIFERIA, CAMINO y, en algunos casos, CONExión, ayudan a perfilar la noción de distancia que se da entre observador-observado (de hecho estas últimas podrían considerarse como subsidiarias al de CENTRO-PERIFERIA). Esta interacción de esquemas de imagen no sólo está en plena concordancia con varias teorías de corte psicológico basadas en la distancia, sino que proporciona una explicación corporeizada (y preconceptual) a fenómenos (frecuentemente de corte conceptual) centrales en estas teorías, como son la noción de distancia psicológica y el nivel de elaboración de las estructuras conceptuales en la Construal Level Theory (Trope y Liberman, 2010) o disociaciones (self-distancing) como las descritas en Kross y Ayduk (2011).

\subsubsection{Metáforas}

Hemos sugerido a lo largo del artículo que para poder percibir los pensamientos y emociones como entes separados del experimentador (así como para poder identificarlos y distinguir entre ellos), necesitamos del poder 'delimitador' de la metáfora. Cada una de las partes identificadas metonímicamente como fragmentos de un todo lo son gracias al poder objetificador de la metáfora. La metáfora, por tanto, tiene un papel importante en tanto que ayuda a dar una forma relativamente definida a los objetos creados como con- 
secuencia de una proyección metonímica inicial, y percibidos gracias a la recuperación de patrones sensorio-motores como los esquemas de imagen. La mayoría de los ejemplos proporcionados a partir de la sección 3.2. muestran de hecho alguna proyección metafórica relacionada con la aprehensión de los pensamientos en las situaciones a las que hacen referencia. Muchas de estas metáforas son de carácter ontológico y pueden desarrollarse discursivamente con mayor o menor grado de especificidad a la hora de dotar al dominio meta (una abstracción como, por ejemplo, el pensamiento) con características del dominio fuente (en este caso, de entidades concretas o con características definidas). Veamos con más detalle algunos de estos casos. ${ }^{26}$ La metáfora conceptual más básica utilizada en la caracterización discursiva del pensamiento a lo largo del corpus, Los PENSAMientos SON ENTIDADES, suele elaborarse más específicamente a través de la personificación y la 'cosificación'.

En el primer caso, la activación de la metáfora LOS PENSAMIENTOS SON ENTIDADES CON VOLUNTAD PROPIA permite la caracterización de los pensamientos como entes volitivos y autónomos, enmarcándolos como personas influyentes a quienes escuchamos ('Vivo con el sentido de quién soy dependiendo de lo que me digan mis pensamientos', ejemplo (2)), como enemigos que invaden nuestro espacio ('...tomamos consciencia de cómo el pensamiento nos ha invadido, nos ha absorbido...' (7)) o que incluso pueden imponer su

\footnotetext{
${ }^{26}$ Retomamos algunos de los ejemplos anteriormente propuestos y proporcionamos otros adicionales.
} 
voluntad sobre la nuestra y 'absorbernos' (7) o 'llevarnos a su terreno' (11):

(11) Si algún pensamiento os lleva hacia donde él quiera, a su terreno, devolvedlo aquí.

La cosificación del pensamiento permite además una doble elaboración. Por un lado, Los PENSAMIENTOS SON OBJETOS (QUe SE MUEVEN POR EL ESPACIO) permite dotar al pensamiento de un carácter ontológico concreto, de modo que el pensamiento no sólo se puede contemplar como cualquier otro fenómeno físico ('Igual que escuchas un sonido, que escuchas una voz, que ves una imagen, contemplas también un pensamiento' (1)), sino que podemos concebir pensamientos concretos como sustancias que entran y salen de nosotros ('... igual que respiras, que entra y sale aire de tu cuerpo, permites que entren y salgan pensamientos' (6)) o como objetos que se mueven con relativa autonomía a través del espacio de observación favoreciendo de este modo su percepción como entidades ajenas al observador ('...si ves que vienen pensamientos y van...' (8); '... el hecho mismo de que tú te des cuenta de que están pasando, y te sitúes y veas eso como algo que pasa y lo dejas pasar...' (9)). El siguiente ejemplo es particularmente ilustrativo en tanto que el instructor hace explícita esta distinción entre observador y pensamiento, y cómo este último se puede llegar a concebir como 'una mera cosa que observas':

(12) Podéis hacer lo que hace la mujer esta, es decir, pensar: ‘¿por qué yo ahora estaba siendo este pensamiento?' ¿qué sería de mí sin 
este pensamiento?' Eso te sitúa en una posición de observador del pensamiento y entonces la situación a la que te llevaba ese pensamiento, sea la que fuera, fundamentalmente las negativas, el estrés, en ese momento se diluye, se convierte en una mera cosa que observas, como una procesión.

Por otro lado, como alternativa complementaria a su representación como objetos con límites definidos, y más particularmente dentro del contexto de instrucción en atención plena, los pensamientos también se modelan como un tipo particular de objetos: LOS PENSAMIENTOS SON CONTENEDORES a cuyo interior el observador puede acceder:

(13) Pero cuando tú 'te quedas con un pensamiento' en concreto [...] ya no estás en el momento presente, estás dentro del pensamiento. Entonces, es cuando estás pensando... porque el pensamiento puede ser que tienes que ir al hospital... y entonces estás en el hospital, preocupada dentro del hospital. Quiero decir, ¿dónde desaparece la sensación de encerrada de la mente? Ya no te das cuenta de las otras partes de tu ser, solamente de eso. Eso es 'quedarse con el pensamiento'.

Es posible, sin embargo, especificar todavía más las características peculiares de estos contendores, y para ello se hace necesario desarrollar la metáfora anterior en términos de la siguiente, LOS PENSAMIENTOS SON CONTENEDORES DEL FUTURO Y DEL PASADO, que junto con EL MOMENTO PRESENTE, EL PASADO Y EL FUTURO SON CONTENDORES, permiten la elaboración discursiva de escenarios como los presentados en (13) y (14). 
(14 ) Estamos aquí, en el presente, y poco a poco, si vamos ampliando la frecuencia con la que tenemos esas experiencias [darse cuenta de haber sido 'absorbido' por un pensamiento, retomar la perspectiva y 'volver' a atender al momento presente] cada vez nos será más fácil estar concentrados en lo que hacemos en cada instante, en cada momento, y al mismo tiempo nos será más fácil identificar qué significan para nosotros cada uno de esos pensamientos que nos estaban absorbiendo y nos llevaban hacia un lugar en el futuro.

De este modo, siguiendo la lógica de estas metáforas, acceder al interior de un pensamiento (que inicialmente podría percibirse como un 'objeto' o una entidad en el espacio de presencia, pero una entidad con tal fuerza sobre nosotros que ha sido capaz de atraernos hasta 'absorbernos') implica 'dejar'27 el momento presente para acceder a su contenido; éste, a su vez, guarda relación en la mayoría de los casos con un recuerdo del pasado o una percepción de una situación hipotéticamente real, o en cualquier caso un espacio mental alternativo al de la situación presente. La interacción de pensamiento 'objeto' o pensamiento 'contendor' es de hecho un paso clave en la práctica de la meditación con atención plena, y se modela precisamente a través de guiones de interacción como los descritos en la siguiente sección. ${ }^{28}$

Antes de tratar el siguiente punto, sin embargo, parece conveniente aquí añadir unos apuntes sobre la caracteriza-

\footnotetext{
${ }^{27}$ Metonímicamente, puesto que no es el observador, sino su mente o atención la que se distancia del momento presente.

${ }^{28}$ Cf. Silvestre-López (en prensa) para una descripción detallada de la forma en que las metáforas EL PENSAMIENTO ES UN OBJETO y EL PENSAMIENTO ES UN CONTENDOR se complementan mutuamente.
} 
ción discursiva del pensamiento en contextos 'populares' (modelos metafóricos utilizados en contextos cotidianos) y de 'atención plena' (modelos utilizados en ámbitos más específicos como los de formación en atención plena). Del mismo modo que ocurre en contextos de uso de la lengua cotidianos en los que hemos de hablar del pensamiento o de las emociones, muchas de las metáforas utilizadas (a veces inconscientemente) en cursos de atención plena pueden considerarse metáforas convencionales (por ejemplo, pensamientos que pasan por la cabeza, miedos que nos atormentan, etc.). Sin embargo, desde nuestro punto de vista, una de las diferencias que caracterizan al discurso de la atención plena (en contraposición a los modelos populares) es que precisamente, aun tratándose de metáforas convencionales a nivel de procesamiento, su uso a nivel comunicativo (Steen, 2013) es frecuentemente deliberado, sobre todo por parte de los instructores, y el cometido del uso de estas metáforas es en muchos casos clarificar conceptos, ayudar a los alumnos a interiorizar una práctica, facilitar algún tipo de experiencia o incluso fomentar el desarrollo de alguna de las facetas que componen la atención plena (SilvestreLópez, 2015, en prensa).

Existe además un continuo de convencionalización de las metáforas utilizadas en ambos contextos cuyos grados de convencionalidad varían según nos movemos de modelos 'populares' a 'especializados', de modo que la misma metáfora puede llegar a considerarse convencional en un contexto y novel en el otro. ${ }^{29}$ Adicionalmente, e independientemente

\footnotetext{
${ }^{29}$ Las implicaciones de esta diferencia, de acuerdo con las propuestas genera-
} 
de las diferencias en cuanto al grado y uso de metáforas convencionales en contextos cotidianos y contextos de formación en atención plena, precisamente en estos últimos el uso deliberado de metáforas aumenta cuando las metáforas son discursivamente más creativas o noveles, sobre todo porque éstas tienden a utilizarse para provocar un efecto concreto en el oyente, con una intención comunicativa explícita (Silvestre-López y Navarro, en revisión). Por ejemplo, enmarcar metafóricamente la contemplación de los pensamientos a través del escenario del observador, el cielo y las nubes es una metáfora común (y relativamente convencionalizada) en el ámbito de la atención plena, pero ya no tanto en contextos de modelos populares; adicionalmente, dependiendo del perfil del alumnado (grupo de población, necesidades, edad, conocimiento, cultura a la que pertenecen, etc.) y el efecto que quiera conseguir, el instructor puede decidir ser más creativo y buscar un dominio fuente que conecte más con sus alumnos (por ejemplo, niños) y crear escenarios, por ejemplo, en los que cada pensamiento se 'vea' como un tren que llega a la estación, y el observador puede decidir subirse y ver qué hay en él o bien esperar a que parta de nuevo y vuelva otro tren.

En cualquier caso, es interesante hacer notar que tanto metáforas convencionales como noveles, tanto no deliberadas como deliberadas son realmente elaboraciones de la estructura básica descrita en este MCI. Es decir, partiendo

\footnotetext{
les de la teoría de la carrera de la metáfora (cf. Gentner et al., 2001; Browdle y Gentner, 2005), se pueden traducir en términos de facilidad de procesamiento (esfuerzo cognitivo) y su activación extendida a lo largo del discurso para procesar y entender un escenario.
} 
de la dinámica del escenario del observador descrito en este en este artículo y obedeciendo a su estructura esencial, la explotan a través de escenarios de mayor o menor grado de elaboración.

\subsubsection{Marcos y guiones}

Parte de la estructura imago-esquemática del escenario del observador puede aprehenderse precisamente a través del conocimiento de los elementos que lo integran. A medida que se adquiere práctica en la atención a todos estos fenómenos, y gracias a la interacción del resto de componentes del MCI (4.2.1.-4.2.3), el meditador se va 'familiarizando' con ellos y puede percibir sensaciones cada vez con mayor sutileza, distinguir diversos tipos de pensamiento (afectivamente positivos, negativos, relacionados con un miedo, con estados mentales positivos, etc.) con unos patrones de comportamiento particulares, percibir más nítidamente emociones y estados e incluso los efectos que todos ellos generan en él como entidad perceptora.

De este modo, la conceptualización de los fenómenos de la percepción, su comportamiento, y la serie de relaciones percibidas entre ellos y el sujeto que los experimenta se estructuran a través de la formación paulatinamente más detallada (esto es, mediante la práctica de la meditación) de marcos (Fillmore y Baker, 2010) y guiones (Schank y Abelson, 1977; Lakoff, 1987). Concretamente los guiones ayudan a estructurar la experiencia vivida con estos fenómenos de una forma similar a los de la conceptualización de emociones propuestos, por ejemplo, por Wierzbicka (1990) o Blanco-Carrión (2011). Cada guion incorpora diversos 
estadios que pueden recuperarse total o parcialmente para la conceptualización de la situación. Un guion genérico de la percepción de estos fenómenos es el siguiente:

(i) Un objeto de la percepción aparece en el espacio de observación.

(ii) Se produce una interacción entre objeto percibido y ente perceptor (la naturaleza de esta interacción determinará los efectos en ambas entidades y viene condicionada por el grado de consciencia y atención desarrollado por el ente perceptor).

(iii) Efectos de esta interacción (para los elementos involucrados).

(iv) Consecuencias o acción derivada (p. ej., efectos y reacciones externas, transmitidas a través de una conducta o acción). Este estadio puede no llegar a darse en algunos casos.

La genericidad de estos estadios se concreta en escenarios particulares de diversos modos dependiendo de los patrones de interacción que pueden llegar a desarrollarse. ${ }^{30}$ Pongamos por ejemplo el escenario de los pensamientos negativos. Cuando un pensamiento negativo ('voy a suspender el examen', 'no llegaré a cumplir con mi trabajo', ‘seré un buen padre?') aparece dentro del espacio de observación, se

\footnotetext{
${ }^{30}$ Uno de los efectos de la práctica de la meditación es precisamente la posibilidad de modificar los patrones de interacción a través de la observación consciente del comportamiento del ente percibido y las reacciones del ente perceptor, de modo que se puede avanzar conscientemente hacia relaciones más saludables y comportamientos más adaptativos.
} 
genera una interacción instantánea con el ente perceptor, de modo que el pensamiento puede llegar a percibirse (dependiendo de parámetros como el tamaño o la distancia percibida), por ejemplo, como una amenaza. A partir de aquí, la interacción entre ambas entidades puede tomar diversos caminos: el pensamiento puede afectar inmediata y negativamente al ente que lo experimenta, por ejemplo, 'tomando fuerza' y generando angustia o ansiedad; alternativamente, el observador (meditador medio-avanzado) puede decidir mantener una posición ecuánime, observar conscientemente el objeto 'desde la distancia' y, al desidentificarse y no tomar acción alguna más que la observación, evita 'alimentar' el pensamiento en sí; adicionalmente, el observador, desde su posición, puede decidir 'involucrarse' (por ejemplo, alejar o desechar mentalmente el objeto o aproximarse y examinarlo con mayor detenimiento para aprender de él), de modo que ambas entidades se ven afectadas como consecuencia de esta acción, etc. Finalmente, los efectos de este tipo de interacción 'interna' determinarán el rango de posibles consecuencias externas (podemos actuar, por ejemplo, desde el nerviosismo o bien desde la calma).

La conceptualización de una situación y su realización lingüística (por ejemplo, la expresión de la emoción del miedo a través de estructuras alternativas como 'tengo miedo' o 'estoy asustado' que ofrece el español) pueden perfilar metonímicamente uno o varios de estos estadios. De este modo, la realización 'tengo miedo' perfila los dos primeros estadios del guion arriba presentado (el resto se rescata inferencialmente). La construcción 'estoy asustado', sin embargo, enfatiza una fase avanzada de los efectos de esta relación (el miedo, 
durante el estadio (ii), por ejemplo, se puede haber apoderado del observador de modo que ahora - estadio (iii) — se ha convertido en un estado que lo envuelve). Las consecuencias en términos de acción (estadio (iv)) podrían ser distintas, por ejemplo, en una situación en la que la 'amenaza' (miedo) percibe como un objeto (obedeciendo a la lógica de la metáfora EL PENSAMIENTO ES UN OBJETO descrita en la sección anterior) que todavía puede llegar a ser 'controlable' (por ejemplo, en términos de observación y desidentificación) en contraposición a un estado extremo en el que estamos inmersos (como desarrollo de la metáfora LOS PENSAMIENTOS SON CONTENEDORES) y del que, por tanto, no podemos salir a voluntad, al menos inicialmente. Una descripción detallada de la combinación de estas y otras metáforas puede encontrarse en (Silvestre-López, en prensa), donde se desarrollan con detalle elaboraciones particulares del MCI de la contemplación en términos de dos guiones derivados del guion genérico aquí presentado; se trata de dos guiones distintos pero complementarios que permiten modelar de una forma coherente y estructurada los patrones de interacción más comunes entre 'meditador y pensamiento' y 'meditador y emoción' en la práctica de meditación formal.

Antes de pasar a las conclusiones, y como en el apartado anterior, cabe enfatizar aquí otra diferencia en cuanto a los modelos de representación utilizados en contextos cotidianos o 'populares' y de 'atención plena'. Si bien en el caso de las metáforas describíamos una divergencia subyacente al grado de convencionalización (metáforas convencionales y noveles utilizadas en el discurso) y al uso deliberado (metáforas utilizadas deliberada o no deliberadamente a nivel comunicativo) 
que de ellas se hace en cada contexto, es posible identificar también otra diferencia importante que puede aprehenderse a través de guiones como los mencionados en esta sección.

Las divergencias entre los modelos populares y los modelos 'de atención plena' comienzan a acrecentarse a medida que la 'relación' del individuo (meditador-perceptor) con eventos mentales o emocionales comienza a verse modificada en términos de patrones de influencia e interacción. Ciertamente, la relación del individuo con estos eventos se ve modificada gracias a la práctica de la atención plena (Miró y Simón, 2012; Cebolla et al., 2014) y viene también facilitada por los instructores en tanto que una de sus tareas es precisamente intentar modificar los modelos 'estándar' de percepción cotidiana de la realidad ${ }^{31} \mathrm{y}$ ayudar a sus alumnos a sustituirlos por modelos más útiles y beneficiosos para ellos $^{32}$ (Silvestre-López, 2016). Estas diferencias son perceptibles, por ejemplo, a través de diferentes patrones de interac-

\footnotetext{
${ }^{31}$ Esto es, modelos con los que los alumnos (y en general, cualquier persona) han aprendido a percibir e interpretar la realidad en el devenir cotidiano y que incluyen, por ejemplo, percepciones culturales (a menudo incluso también incuestionables, puesto que la influencia de la cultura y nuestro entorno es cotidianamente difícil de identificar) que definen la imagen que tenemos de nosotros mismos en términos de nuestro trabajo o posición social, así como creencias infundadas que generan sufrimiento como 'tengo que conseguir esta meta para ser feliz'.

${ }^{32}$ Por ejemplo, atender con aceptación y sin juicio tanto a fenómenos externos como internos ayuda a fomentar efectos relacionados con la defusión cognitiva, de modo que se incrementa la 'perspectiva del observador' y con ella los pensamientos - tanto positivos como negativos, incluyendo proyecciones como nuestra autoimagen o metas a alcanzar - pueden percibirse como meras representaciones mentales (interpretaciones que no se corresponden con la realidad) en lugar de como 'realidades absolutas' que de otro modo - a través de modelos 'estándar' de percepción - podrían alterar nuestro estado emocional y guiarían nuestra acción cotidiana no siempre con las mejores consecuencias.
} 
ción con el pensamiento o con emociones dentro del guion de comportamiento de cada evento mental. De este modo, en los modelos utilizados por 'no meditadores', es decir, aquellos más cercanos a los 'modelos populares', los estadios o fases enfatizados (tanto conceptual como lingüísticamente) en cada guion pueden llegar a divergir sustancialmente con respecto a los utilizados por meditadores más avanza$\operatorname{dos}^{33}$ (Silvestre-López, 2015). Así, en el primer caso se enfatizan estadios en los que el experimentador -en los casos en que es consciente de la presencia de pensamientos o emociones - tiene una visión vaga de su naturaleza debido a que no existe en él la actitud de observación (intención de prestarles atención), aceptación, apertura y curiosidad hacia ellos. En consonancia con esto, también se enfatizan estadios iniciales en los que estos fenómenos mentales tienen (todavía) un considerable nivel de influencia (e incluso control) sobre el observador, de modo que, al no ser atendidos, suelen tomar fuerza y 'atrapar' al experimentador (Silvestre-López, en prensa). En el caso de meditadores avanzados, sin embargo, tienden a enfatizarse principalmente estadios de desidentificación y 'observación pura' (casi sin interacción o influencia entre ente experimentador y objetos de la percepción) relacionados con la contemplación de la naturaleza de pensamientos o emociones como 'objetos' en el espacio

\footnotetext{
${ }^{33}$ Incluso en el caso de meditadores avanzados, los modelos utilizados pueden ser de diversa naturaleza dependiendo no sólo de la cultura en la que están inmersos, sino también del tipo de prácticas que acostumbran a emplear y sobre todo de la tradición meditativa a la que pertenecen, que puede además añadir tintes religiosos que traen consigo caracterizaciones metafóricas o imágenes culturales particulares de su contexto (Silvestre-López y Navarro, en prensa).
} 
de presencia. Se caracteriza a los pensamientos y emociones de una forma más elaborada (por ejemplo como entidades que se perciben siempre como diferenciadas del observador y presentan patrones de comportamiento/influencia definidos) y una relación con ellos basada en la apertura y aceptación (en lugar del apego o rechazo, por ejemplo).

En definitiva, mientras que los modelos utilizados cotidianamente (contextos populares) parecen quedarse en la mera caracterización del pensamiento o de las emociones como fuerzas o entidades (o entidades que ejercen fuerza sobre el experimentador) siguiendo el molde proporcionado por modelos socioculturales preestablecidos (Kövecses, 2000), los modelos utilizados en contextos de atención plena tienden a enfatizar más claramente parámetros asociados a la práctica misma, principalmente aquellos relacionados con la actitud del practicante (aceptación, rechazo, juicio, ecuanimidad, etc.) y la interacción entre el observador y lo observado (explotando en este último caso sobre todo aquellos asociados con la desidentificación, la separación y la distancia entre ambas entidades). Del mismo modo, mientras que los modelos utilizados en contextos de atención plena necesitan beber de los modelos culturales que sustentan la conceptualización de los fenómenos a observar (imagen del individuo, pensamiento, emociones, etc.) para poder hacer la experiencia comunicativamente accesible - sobre todo en estadios iniciales-, la necesidad de expresar los fundamentos de la práctica y el cúmulo de vivencias - totalmente nuevas, en el caso de los alumnos- que de ella se deriva de un modo más preciso y vívido da lugar a la elaboración de estos modelos en 'diseños más 
avanzados' de los mismos, ${ }^{34}$ es decir, diseños evolucionados que son ya en sí distintos a los culturalmente establecidos 'por defecto'.

\section{Conclusiones}

Comenzábamos este artículo sugiriendo que ni la temática ni los conceptos en él tratados son nuevos. Si bien esto es cierto, este trabajo sí proporciona una aportación novedosa tanto al campo de la atención plena como al de la lingüística cognitiva: la presentación de un modelo primordial de representación de la experiencia que, integrando elementos experienciales de primera mano (vivenciales) y datos de corte lingüístico, abre las puertas a varias líneas de investigación en ambos campos.

De este modo, la descripción del modelo de representación de la experiencia que se ha llevado a cabo en este artículo nos ha permitido introducir el 'espacio de presencia' y describir (mostrando de este modo que su descripción es posible) algunas de las percepciones fenomenológicas que 'en él ocurren' a través de los parámetros esenciales que componen un MCI. El tema abordado sin embargo es complejo y por tanto difícilmente encapsulable en la extensión razonable de un único artículo; los aspectos aquí sugeridos han

\footnotetext{
${ }^{34}$ Nos referimos a elaboraciones metafóricas más específicas como las relativas a los ejemplos (13) y (14), o por ejemplo la caracterización del pensamiento de modos relativamente 'noveles' (como una nube o un tren) descrita en esta sección.
} 
de tratarse extensamente, por tanto, en publicaciones adicionales (Silvestre-López, en preparación; en prensa).

\subsection{Comprobación psicológica de la propuesta}

La estructura de este MCI se ha derivado a partir de la base experiencial que proporciona la práctica de la atención plena y el análisis del discurso de instructores y aprendices en el contexto de cursos de formación en atención plena. Es necesario llevar a cabo otra serie de estudios que aporten validez psicológica a los datos aquí aportados. De hecho, el enfoque aquí presentado está concebido como el punto de partida para otra serie de estudios desde el campo de la psicología. Por ejemplo, aunque las propuestas aquí descritas no son nuevas dentro del cognitivismo, es necesario llevar a cabo estudios de carácter extralingüístico que arrojen más luz sobre procesos concretos como el reciclaje de estructuras (tanto de carácter preconceptual como conceptual) utilizadas en la percepción ordinaria 'exterior' hacia la 'interior', el papel de la metonimia en procesos relacionados con la desidentificación del individuo con el pensamiento, así como el estatus mental de las metáforas propuestas en este estudio.

\subsection{Sobre la influencia de factores externos}

en la conceptualización de la experiencia

En este estudio hemos sugerido que las representaciones mentales que permiten la aprehensión del pensamiento parten del nivel de experiencia directa. Sin embargo, al igual 
que el uso de la lengua refuerza la activación de metáforas mentales (Casasanto, 2010), los modelos que compartimos lingüística, culturalmente o dentro de una comunidad específica (por ejemplo, una tradición de meditación o grupo de practicantes) podrían también incidir en la activación más frecuente de representaciones mentales específicas en los miembros de dicha comunidad (cf. Ibarretxe-Antuñano, 2013a, b). El presente trabajo abre también una nueva línea de investigación sobre el tipo de influencia que los MCIs heredados lingüística y culturalmente pueden ejercer precisamente en la configuración de las metáforas mentales asociadas a la contemplación de los fenómenos internos. Esta línea puede desarrollarse desde dos perspectivas complementarias: la psicológica, en la línea de estudios como Casasanto (2010), y la lingüística. En cuanto a esta última, proponemos que el estudio de metáforas mentales utilizadas en la experiencia de la meditación a través del lenguaje es no sólo posible sino operacionalmente viable en tanto que la lengua refleja (cada lengua de un modo) este tipo de metáforas mentales. Las implicaciones para un estudio de corte contrastivo son obvias: el estudio de este tipo de metáforas a través de diversas lenguas (preferentemente a través de corpus específicos que aglutinen la producción en términos de géneros discursivos o comunidades lingüísticas) puede ayudar a perfilar más claramente el tipo de metáforas mentales que suelen activarse en la 'experiencia directa, vivencial,' de la meditación. 


\subsection{Otros estudios y aplicaciones derivadas}

Dado que el desarrollo de sinergias de colaboración entre diversas áreas es deseable para avanzar en este ámbito, actualmente se ha abierto una línea de colaboración entre un equipo interdisciplinar de lingüistas y psicólogos para abordar algunos de los aspectos tratados en este artículo. Uno de ellos es el estudio de las posibles concomitancias y divergencias entre los modelos de representación de la experiencia comúnmente activados por no practicantes y los modelos más representativos de la práctica de la atención plena (principalmente relacionados con meditadores). Dar cuenta de estas divergencias requiere un estudio lingüístico que involucre un corpus mucho mayor al utilizado en este artículo (corpus que se está compilando y transcribiendo en la actualidad, derivado de grabaciones en inglés y en español), pero también necesita de la colaboración con psicólogos en tanto que uno de las líneas derivadas de esta línea de investigación es la detección de patrones de representación de la experiencia a través de los modelos discursivos utilizados dentro de contextos culturales diversos (influencia de los modelos de su cultura y su lengua), con alumnos de perfiles sociodemográficos distintos (edad, educación, contexto social, etc.) en contextos psicoeducativos y clínicos (cf. Campos y Cebolla, 2016).

Si bien poder describir los modelos a través de los que se construye el discurso en cada uno de estos contextos es ya meritorio en sí mismo en términos de análisis lingüístico, el paso siguiente en esta línea de investigación es intentar detectar también la potencial influencia de los modelos me- 
tafóricos discursivos en las representaciones mentales de los practicantes, y averiguar también si, en su caso, el uso consciente y deliberado de metáforas puede tener una incidencia mesurable en los alumnos, su práctica y el desarrollo de estas habilidades. En caso afirmativo, la elección consciente y uso deliberado de patrones metafóricos adecuados podría convertirse en una potente herramienta pedagógica en contextos de instrucción en atención plena (Silvestre-López, 2015, 2016)

\section{Agradecimientos}

Vayan mis agradecimientos a los maestros que han ayudado a que esta publicación sea posible, a los evaluadores de este artículo por sus valiosos comentarios y sugerencias, al instituto IULMA y a la Universitat Jaume I (proyecto P1.1A2014-2).

\section{Bibliografía}

Baer, Ruth y Jennifer Krietemeyer (2006), “Overview of Mindfulness- and Acceptance-Based Treatment Approaches", en R. Baer (ed.), Mindfulness-based Treatment Approaches: Clinician's Guide to Evidence Base and Applications, Ámsterdam, Elsevier Academic Press, pp. 3-27.

BarracA, Jorge (2011), “ ¿Aceptación o Control Mental? Terapias de aceptación y mindfulness frente a las téc- 
nicas cognitivo-conductuales para la eliminación de pensamientos intrusos", Análisis y Modificación de Conducta, 37, pp. 43-63.

Bergen, Benjamin (2012), Louder than words: The new science of how the mind makes meaning, Nueva York, Basic Books.

Berntson, Gary y John Cacioppo (2009) (eds.), Handbook of Neuroscience for the Behavioural Sciences, vol. 2, Hoboken, NJ, John Wiley \& Sons.

Bierwiaczonek, Boguslaw (2012), Metonymy in Language, Thought and Brain, Sheffield, Equinox.

Blanco-Carrión, Olga (2011), "Emotion and Violent Event Analysis in 'A Married Woman' by Manju Kapur", en C.Gámez y A. Navarro (eds.), India in the World, Lancaster, Cambridge Scholars, pp. 143-156.

Browdle, Brian F. y Dedre Gentner (2005), “The Career of Metaphor". Psychological Review 112(1), pp. 193216.

Brown, Kirk, Richard Ryan, Jon Creswell y Christopher Niemiec (2008), "Beyond Me: Mindful Responses to Social Threat", en H. Wayment y J. Bauer (eds.), Transcending Self-Interest: Psychological Explorations of the Quiet Ego, Washington, DC, APA, pp. 75-84.

Campos, Daniel y Ausiàs Cebolla (2016), "Enseñar mindfulness: Contextos de instrucción y pedagogía", Revista de Psicoterapia, 27(103), pp. 103-118.

Casasanto, Daniel (2010), "Space for Thinking”, en V. Evans y P.Chilton (eds.), Language, Cognition, and Space: State of the Art and New Directions, Londres, Equinox, pp. 453-478. 
Casasanto, Daniel (2013), "Development of metaphorical Thinking: The Role of Language", en M. Borkent, B. Dancygier y J. Hinnell (eds.), Language and the creative mind, Stanford, CSLI Publications, pp. 3-18.

Cebolla, Ausiàs., Javier García-Campayo y Marcelo Demarzo (2014) (eds.), Mindfulness y ciencia. De la tradición a la modernidad, Madrid, Alianza.

Chalmers, David (1996), The Conscious Mind. In Search of a Fundamental Theory, Oxford/NY, OUP.

Clark, Andy y David Chalmers (1998), "The Extended Mind", Analysis, 58, pp. 7-19.

Collins, Susan, Neharika Chawla, Sharon Hsu, Joel Grow, Jacqueline Otto y G. Alan Marlatt (2009), "Language-Based Measures of Mindfulness: Initial Validity and Clinical Utility", Psychology of Addictive Behaviors, 23(4), pp. 743-749.

Eisendrath, Stuart, Margaret Chartier y M. McLane (2011), "Adapting Mindfulness-Based Cognitive Therapy for Treatment-Resistant Depression: A Clinical Case Study", Cognitive and Behavioral Practice, 18(3), pp. 362-370.

Evans, Vyvyan (2010), "Perceptual Basis of Spatial Representation", en V. Evans y P. Chilton (eds.), Language, Cognition, and Space: State of the Art and New Directions, Londres, Equinox, pp. 21-48.

Evans, Vyvyan (2013), "Metaphor, Lexical Concepts, and Figurative Meaning Construction", Journal of Cognitive Semiotics, 5(1-2), pp. 73-107.

Fillmore, Charles. J. y Collin Baker (2010), "A Frames Approach to Semantic Analysis" en B. Heine y N. 
Heiko (eds.), The Oxford Handbook of Linguistic Analysis, Nueva York, The Oxford University Press, pp. 313339.

Francesconi, Denis (2010), The Embodied Mind: Mindfulness Meditation as Experiential Learning in Adult Education, tesis doctoral, Trento, Universidad de Trento.

Gibbs, Raymond. (2011), "Evaluating Conceptual Metaphor Theory”, Discourse Processes, 48(8), pp. 529-562.

García Campayo, Javier y Marcelo Demarzo (2015), Mindfulness: Curiosidad y Aceptación, Barcelona, Ilus Books.

Gentner, Dredre, Brian F. Bowdle, Phillip Wolff y Consuel. Boronat (2001), "Metaphor is Like Analogy", en D.Gentner, K. J. Holyoak y B. N. Kokinov (eds.), The Analogical Mind: Perspectives from Cognitive Science, Cambridge, MIT, pp. 199-253.

Grady, Joseph (2007), "Metaphor", en D. Geeraerts y H. Cuyckens (eds.), Handbook of Cognitive Linguistics, Oxford, OUP, pp. 188-213.

Hall, Edward (1966), The Hidden Dimension, Nueva York, Anchor Books.

Hayes, Steven, Dermot Barnes-Holmes y Bryan Roche (eds.) (2001), Relational Frame Theory: A Post-Skinnerian Account of Human Language and Cognition, Nueva York, Plenum Press.

Hayes, Steven y Chad Shenk (2004), “Operationalizing Mindfulness Without Unnecessary Attachments”, Clinical Psychology: Science and Practice, 11, pp. 249-254.

Hölzel, Britta, Sara Lazar, Tim Gard, Zev Schuman-Olivier, David R. Vago y Ulrich Ott 
(2011), "How does Mindfulness Meditation Work? Proposing Mechanisms of Action from a Conceptual and Neural Perspective, Perspectives on Psychological Science, 6(6), pp, 537-559.

Hulburt, Russell (2011), Investigating Pristine Inner Experience, Cambridge, CUP.

Ibarretxe-Antuñano, Iraide (2011), "Metáforas de la percepción: una aproximación desde la Lingüística Cognitiva”, en Cristian Santibáñez y Jorge Osorio (eds.), Recorridos de la metáfora: mente, espacio y diálogo, Concepción, Cosmigonon, pp. 141-166.

Ibarretxe-Antuñano, Iraide (2013a), "The Power of the Senses and the Role of Culture in Metaphor and Language", en Rosario Caballero y Javier Diaz-Vera (eds.), Sensuous Cognition: Explorations into Human Sentience - Imagination, (E)motion and Perception, Berlín/ Nueva York, Mouton de Gruyter, pp. 109-133.

IbarretXe-Antuñano, Iraide (2013b), "The Relationship between Conceptual Metaphor and Culture", Intercultural Pragmatics, 10(2), pp. 315-339.

IbarretXe-Antuñano, Iraide y Javier Valenzuela (2012), Lingüistica Cognitiva, Barcelona, Anthropos. Johnson, Mark (1987), The Body in the Mind: The Bodily Basis of Meaning, Imagination, and Reason, Chicago, University of Chicago Press.

Kabat-Zinn, J. (2003), "Mindfulness-based Interventions in Context: Past, Present, and Future. Clinical Psychology: Science and Practice, 10, pp. 144-156.

Kerr, Catherine, Krishnapriya Josyula y Ronnie LitTENBERg (2011), “Developing an Observing Attitude: 
An Analysis of Meditation Diaries in an MBSR Clinical Trial", Clinical Psychology and Psychotherapy, 18(1), pp. 80-93.

Kövecses, Zoltán (1990), Emotion Concepts, Berlín/Nueva York, Springer-Verlag.

Kövecses, Zoltán (2000), Metaphor and Emotion, Cambridge, CUP.

Kross, Ethan y Ozlem Ayduk (2011), "Making Meaning out of Negative Experiences by Self-Distancing", Current Directions in Psychological Science, 20(3), pp. 187-191. Lakoff, George (1987), Women, Fire, and Dangerous Things: What Categories Reveal about the Mind, Chicago, University of Chicago Press.

LAKoff, George (1996), "Sorry, I'm not Myself Today: the Metaphor System for Conceptualizing the Self”, en G. Fauconnier y E. Sweetser (eds.), Spaces, Worlds, and Grammar, Chicago, University of Chicago Press, pp. 91-123.

Lakoff, George y Mark Johnson (1999), Philosophy in the Flesh. The Embodied Mind and its Challenge to Western Though, Nueva York, Basic Books.

Lakoff, George y Mark Johnson (1980), Metaphors we Live by, Chicago/Londres, Chicago University Press.

Langacker, Ronald (2008), Cognitive Grammar. A Basic Introduction, Oxford, OUP.

Mañas, Israel, Clemente Franco, M.Dolores Gil y Consolación Gil (2014), "Educación consciente: Mindfulness (Atención Plena) en el ámbito educativo. Educadores conscientes formando a seres humanos conscientes", en R. Soriano y P.Cruz (eds.), Alianza de 
civilizaciones, políticas migratorias y educación, Sevilla, Aconcagua Libros, pp. 193-229.

Miró, M.Teresa y Vicente Simón (2012) (eds.), “Mindfulness en la práctica clínica, Bilbao, Desclée de Brower.

Peña, M.Sandra y Ruiz de Mendoza, F. José (2009), "The Metonymic and Metaphoric Grounding of two Image-Schema Transformations", en K. Panther, L. Thornburg y A. Barcelona (eds.), Metonymy and Metaphor in Grammar, Ámsterdam/Filadelfia, John Benjamins, pp.339-361.

Ruiz de Mendoza, F. José (2014), “Mapping Concepts: Understanding Figurative Thought from a Cognitive-Linguistic Perspective", RESLA, 27(1), pp. 187-207.

Safran, Jeremy y Zindel Segal (1990), Interpersonal Process in Cognitive Therapy, Nueva York, The Guilford Press.

Santiago, Julio, Antonio Román y Mark Ouellet (2011), "Flexible Foundations of Abstract Thought: A Review and a Theory", en T. Schubert y A. Maass (eds.), Spatial Dimensions of Social Thought, Berlín, Mouton de Gruyter, pp. 39-108.

Shapiro, Shauna L., Linda E. Carlson, John, A. Astin y Benedict Freedman (2006), "Mechanisms of Mindfulnesss", Journal of Clinical Psychology, 62, pp. 373-386. Schank, Roger C. y Robert Abelson (1977), Scripts, Plans, Goals, and Understanding, Hillsdale, NJ, Earlbaum Assoc.

Silvestre-López, A. J. (2016), “The Discourse of Mindfulness: What Language Reveals about the Mindfulness Experience”, en P. Ordóñez-López y N. Edo-Marzà 
(eds.), New Insights into the Analysis of Medical Discourse in Professional, Academic and Popular Settings, Bristol, Multilingual Matters, pp. 173-198.

Silvestre-López, A. J. (en preparación), "Mindfulness and the Imago-Schematic Structure of the Space of Presence".

Silvestre-López, A. J. (2015), "Metaphors we Meditate by: Deliberate Metaphor as a Tool for Mindfulness Training", en I. Navarro (Presidencia $4^{\text {th }}$ International Conference on Metaphor and Discourse). Congreso celebrado en la Universitat Jaume I de Castellón, España.

Silvestre-López, A. J. (Junio de 2016), "El Discurso de Mindfulness: La Metáfora como Herramienta en Contextos de Instrucción", en J. García-Campayo (Presidencia 3rd International Meeting on Mindfulness). Congreso celebrado en la Universidad de Zaragoza, España.

Silvestre-López, A. J. e Ignasi Navarro (en prensa), "Metaphors in the Conceptualization of Meditative Practices", Metaphor and the Social World (Special Issue on Metaphor in Religion and Spirituality).

Soler, Joaquim, Alba Franquesa, Albert Feliu-Soler, Ausiàs Cebolla, Javier García-Campayo, Rosa Tejedormarcelo Demarzo, Rosa Baños, J. Carlos Pascual y María J. Portella (2014), "Assessing Decentering: Validation, Psychometric Properties, and Clinical Usefulness of the Experiences Questionnaire in a Spanish Sample", Behavior Therapy, 45(6), pp. 863-871. 
Steen, Gerard (2013), "Deliberate Metaphor Affords Conscious Metaphorical Cognition”, Journal of Cognitive Semiotics, 5(1-2), pp.179-197.

Steen, Gerard (2014), “The Cognitive-Linguistic Revolution in Metaphor Studies", en J. Littlemore y J. Taylor (eds.), The Bloomsbury Companion to Cognitive Linguistics, London, Continuum, pp. 117-142.

Steen, Gerard, Gudrun Reijnierse y Christian BurgERS (2014), "When do Natural Language Metaphors Influence Reasoning? A Follow-Up Study to Thibodeau and Boroditsky (2013)", PLoSOne 9 (12), e113536. doi:10.1371/journal.pone.01135

Talmy, Leonhard (1996), "Fictive Motion in Language and "Ception"', en P. Bloom, M. Peterson, L. Nadel y M. Garrett (eds.), Language and Space, Cambridge, MA, MIT, pp. 211-276.

Talmy, Leonhard (2000), Toward a Cognitive Semantics. Volume I, Cambridge, MA/Londres, MIT.

Trope, YaAcov y Nira Liberman (2010), "Construal-Level Theory of Psychological Distance", Psychological Review, 117(2), pp. 440-463.

Thibodeau, Paul y Lera Boroditsky (2011), Metaphors we Think With: The Role of Metaphor in Reasoning, PLoSOne6 (2): e16782. doi:10.1371/journal. pone. 0016782

Thibodeau, Paul y Lera Boroditsky (2013), Natural Language Metaphors Covertly Influence Reasoning, PloSOne 8: e52961. doi: 10.1371/journal.pone.0052961. 
Varela, Francisco, Evan Thompson y Eleanor Rosch (1991), The Embodied Mind: Cognitive Science and Human Experience, Cambridge, MIT Press.

Varra, A. Alethea, Claudia Drossel y Stephen C. HaYEs (2009), "The Use of Metaphor to Establish Acceptance and Mindfulness", en D. Fabrizio (ed.), Clinical Handbook of Mindfulness, Nueva York, Springer, pp. 111-123.

Wierzbicka, Anna (1990), "Defining Emotion Concepts", Cognitive Science, 16(4), pp. 539-581. 